\title{
Reliability Assessment and Study of Quality Control Tools on Intermixer and Dump Mill of a Tyre Manufacturing Industry
}

\author{
M. Prashanth Pai ${ }^{{ }^{*}}$, C. G. Ramachandra ${ }^{2}$, T. R. Srinivas ${ }^{3}$ and M. J. Raghavendra ${ }^{2}$ \\ ${ }^{1}$ Department of Mechanical Engineering, P.A College of Engineering, Mangaluru, India. \\ ${ }^{2}$ Department of Mechanical Engineering, Srinivas Institute of Technology, Mangaluru, India. \\ ${ }^{3}$ Department of Industrial \& Production Engineering, SJCE, Mysuru, India.
}

\begin{abstract}
Quality plays a very important role in today's highly competitive industrial environment. Quality leads to an improvement in the productivity. Quality control tools are used to solve more than $90 \%$ of the problems faced by the organizations in improving its effectiveness and meeting the customer expectation on a continuous basis. The success of the quality control procedure depends greatly on the method of data collection and its accuracy. Quality control tools are used worldwide in manufacturing industries for continual improvement and are implemented in different steps of manufacturing process to define the problem, measure its impact, finding out its root cause and its removal to ensure the production of non-defective items. The present work includes collection of failure data of intermix and dump mill of a tyre manufacturing unit located in Karnataka. The failure data collected for one year has been analysed to find out the major causes of breakdown. Quality control tools such as Pareto chart, Bar chart, Histogram, Fish bone diagram have been used to find out the root causes and identifying the action plans to eradicate them. Reliability assessment (theoretical) of intermix and dump mill has been conducted using the failure data. The reliability and maintainability curves speak about the present state of working of maintenance department in regard to addressing of breakdown problems and also help in setting future working standards.
\end{abstract}

\section{Introduction}

Machinery and other service facilities of any industry are continuously subjected to deterioration upon their use and exposure to environmental conditions. With the passage of time, machinery will be subjected to wear and tear and their performance as well as reliability decreases. Maintenance helps the plant and machinery to be maintained in good operating condition so as to maximize the output, reliability and profitability [1]. A good

\footnotetext{
${ }^{*}$ Corresponding author: shanth.pai@gmail.com
} 
maintenance system also contributes to efficiency, timely delivery of goods and services, quality, safety and customer satisfaction [2]. Preventive, predictive, reliability-centred and total productive maintenance are some of the widely used maintenance techniques in industries. Failure analysis is the process of collecting and analyzing data to identify the root causes of a failure and to determine corrective actions for them. Failure data are the backbone of reliability studies as they provide very useful information to reliability engineers, design engineers and managers [3]. It is a vital tool used in the development of maintenance strategy for any equipment, development of new products and in the improvement of existing products. Various sources of collecting failure data are available, but inspection records, log books generated by maintenance, quality control or manufacturing groups are widely used.

Quality control helps to maintain the desirable product quality in order to increase customer satisfaction and profitability. The quality control tools help to identify the problems, prevent errors due to omissions or carelessness, confirm the effect of improvement and determine whether the assumed cause is right or wrong. Some of the important quality control tools include brainstorming, bar charts and histograms, Pareto charts, Cause and effect diagram, etc. [2]. Brainstorming is a technique of generating a large number of ideas for identifying or solving the root causes of a problem from the members of a team in a structural manner. Cause and effect diagram results from the brainstorming session. The pictorial nature of histogram helps to see patterns that are difficult to see in a simple table of numbers. Pareto charts are very useful in the easy identification of the problems.

Thuleswar Nath [4] has carried out his work on a pouch machine which was used in vertical filling and sealing in a cosmetic plant. The failures of the machine resulted in nonavailability of the system and thus affected production. Pareto analysis was used to figure out the major contributors towards downtime losses. Why-why technique was used to better explain the reasons behind breakdowns. Based on the root cause analysis, a new preventive maintenance checklist was prepared for the pouch machine. Prashanth Pai M et al. [5] have carried out their work on a three roll calendar machine in a tyre manufacturing industry. The breakdown details of three roll calendar were analysed to determine the optimal inspection frequency of its critical parts by using a mathematical and hypothetic model. The model was aimed at maximising the profit and minimising the downtime of the selected critical machine.

Praveen Kumar R [6] has carried out his work in view of increasing the availability of 1000 Ton Hydraulic Press machine, maximizing production capacity and improving its preventive maintenance schedule. The breakdown details of the critical parts of the machine were collected, root causes of failure were determined by Fishbone diagram and why-why analysis to reduce idle time and optimize plant performance. Deepak [7] has carried out his work in a bicycle industry to reduce the rejection of bicycle rims by the application of Pareto chart and Fishbone diagram. Process parameters such as heating voltage, temperature and quality of the heated water, time of chemical coating process and chemical composition of material etc., have the influence on the quality of final product which needs to be controlled in order to reduce wastage. Jayant Chandrakar [8] has carried out his work in a food processing plant. Why-why analysis, fish-bone diagram were used to develop and improve preventive maintenance checklist for the machine.

In this work, a critical machine namely 'Intermixer and Dump mill' from a tyre industry (located in the southern part of Karnataka) has been selected for the analysis. The intermixer and dump mill unit (figure 1) had frequent breakdowns in the selected year and hampered the productivity of the plant to a greater extent compared to all other critical 
machines in the plant and hence it was selected for the analysis. The Intermixer is used to prepare the rubber compound. Measured ingredients like natural or synthetic rubber, sulphur, carbon, oil, zinc oxide and other chemicals are placed onto a conveyor system and the intermixer is charged to initiate the mixing process. A ram pushes the materials into the mixing chamber and two rotors mix rubber with the chemical agents. Mixing will be quick and uniform compound will be obtained. At the end of the mixing cycle, rubber is placed onto a dump mill, which shapes the rubber into flat, long strips by forcing it through two set rolls rotating in different directions at different speeds.

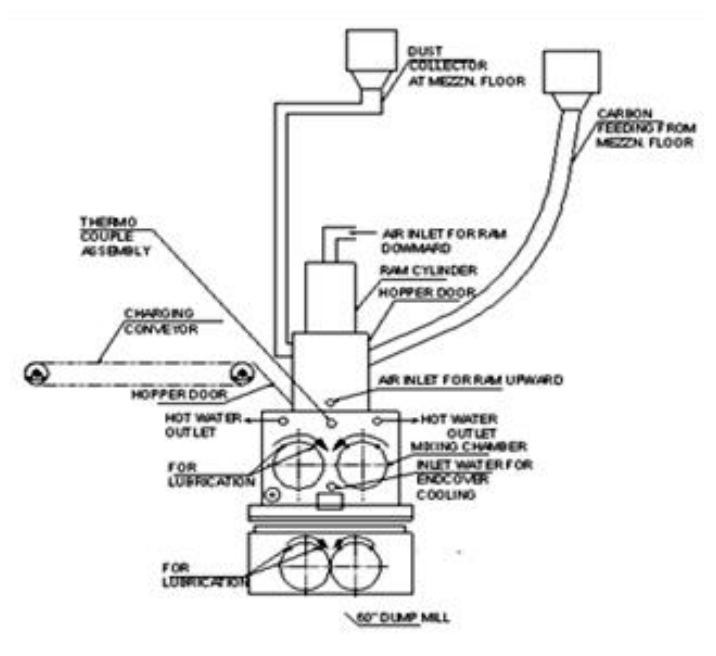

Fig. 1. Block diagram of intermix line with dump mill

\section{Methodology}

In this work, the breakdown data of intermixer and dump mill for one particular year were collected from the maintenance log books. Monthwise data showing date and time of breakdown, breakdown details, repair time and maintenance action taken were noted down for 12 months of the year. The failure data was analysed with the help of quality control tools such as Bar charts and Histograms, Pareto charts and Fish bone diagram to find out the root causes of failure and the possible ways to eliminate them. Production losses due to important causes of breakdown were also calculated. Brainstorming sessions for the five major subsystems of the machine resulted in a fishbone diagram showing the causes of failure and possible corrective actions. A troubleshooting chart was also developed. Finally reliability assessment (theoretical) of the intermixer and dump mill was carried out by using the failure data.

\section{Results and Discussions}

\subsection{Failure data analysis}

For each month, failure data was analysed and Pareto chart was drawn showing each cause of failure, breakdown time in hours and percentage breakdown for each cause. Monthwise total available hours, total breakdown time in hours, total repair time in hours, total inspection time in hours and percentage breakdown were tabulated (table 1) and shown in the bar chart (figure 2). After completing the monthwise analysis, 9 important causes of 
breakdown were identified and their repetitiveness for the year was tabulated (table 2). The breakdown time and percentage breakdown were tabulated (table 2) for nine causes of breakdown and shown in the Pareto chart (figure 3).

\subsection{Production Loss Calculations}

Production loss is calculated on the basis of average monthly production in tons to the average available hours per month.

The average monthly production $=1000$ tons

The average available hours per month $=7460 / 12=621.66 \mathrm{hrs}$.

Table 1. Monthwise Breakdown details for the Intermix and Dump mill

\begin{tabular}{|c|c|c|c|c|c|c|}
\hline Month & $\begin{array}{c}\text { Total } \\
\text { available } \\
\text { Hours }\end{array}$ & $\begin{array}{c}\text { No. of } \\
\text { breakdowns } \\
\text { in the } \\
\text { month }\end{array}$ & $\begin{array}{c}\text { Total } \\
\text { breakdown } \\
\text { time in Hrs }\end{array}$ & $\begin{array}{c}\text { Total } \\
\text { repair time } \\
\text { in Hrs }\end{array}$ & $\begin{array}{c}\text { Total } \\
\text { Inspection } \\
\text { time in Hrs }\end{array}$ & $\begin{array}{c}\text { Percentage } \\
\text { breakdown } \\
\text { [\%] }\end{array}$ \\
\hline Jan & 632 & 12 & 33.5 & 28.91 & 4.58 & 5.3 \\
\hline Feb & 560 & 4 & 4.75 & 4 & 0.75 & 0.84 \\
\hline Mar & 626 & 10 & 16.25 & 13.5 & 2.75 & 2.59 \\
\hline Apr & 624 & 6 & 16.25 & 14.58 & 2.16 & 2.68 \\
\hline May & 632 & 9 & 17.5 & 14.83 & 2.66 & 2.76 \\
\hline Jun & 648 & 4 & 10.5 & 9 & 1.5 & 1.62 \\
\hline Jul & 648 & 5 & 11.5 & 9.66 & 1.83 & 1.77 \\
\hline Aug & 632 & 6 & 18.5 & 16.66 & 1.83 & 2.92 \\
\hline Sep & 592 & 7 & 18.5 & 16 & 2.5 & 3.12 \\
\hline Oct & 618 & 6 & 19 & 16.5 & 2.5 & 3.07 \\
\hline Nov & 576 & 7 & 25.5 & 22.91 & 2.58 & 4.42 \\
\hline Dec & 672 & 7 & 36.5 & 33.25 & 3.25 & 5.43 \\
\hline Total & 7460 & 83 & 228.75 & 199.8 & 28.89 & \\
\hline
\end{tabular}

Table 2. Total Outage due to Breakdown Hours for Intermix and Dump mill

\begin{tabular}{|c|l|c|c|c|}
\hline $\begin{array}{c}\text { Sl. } \\
\text { No. }\end{array}$ & \multicolumn{1}{|c|}{ Cause of breakdown } & $\begin{array}{c}\text { No. of times } \\
\text { occurred } \\
\text { in the year }\end{array}$ & $\begin{array}{c}\text { Breakdown } \\
\text { in hrs }\end{array}$ & $\begin{array}{c}\text { Percentage } \\
\text { Breakdown }\end{array}$ \\
\hline 1 & Drop Door Assembly & 32 & 74.25 & 32.45 \\
\hline 2 & Ram Assembly & 11 & 24.25 & 10.60 \\
\hline 3 & Lubrication System/Oil Circulation & 11 & 19.5 & 8.52 \\
\hline 4 & Hopper Door Assembly & 05 & 9.5 & 4.15 \\
\hline 5 & Instrumentation/Temperature System & 03 & 11 & 4.80 \\
\hline 6 & Water Circulation System & 03 & 6 & 2.62 \\
\hline 7 & Pneumatic Circuits & 01 & 3 & 1.31 \\
\hline 8 & Rotor/Bearing/Coupling & 08 & 58.25 & 25.46 \\
\hline 9 & Dump Mill & 09 & 23 & 10.05 \\
\hline
\end{tabular}




\subsubsection{Lost production per hour}

Total breakdown hours in the year equal to 228.75 and the intermix and dump mill was available for 7460 hours in the year. The annual production was 12000 tons.

Average hourly production $=(12000 \times 1000) / 7460=1608.6 \mathrm{~kg} / \mathrm{hour}$

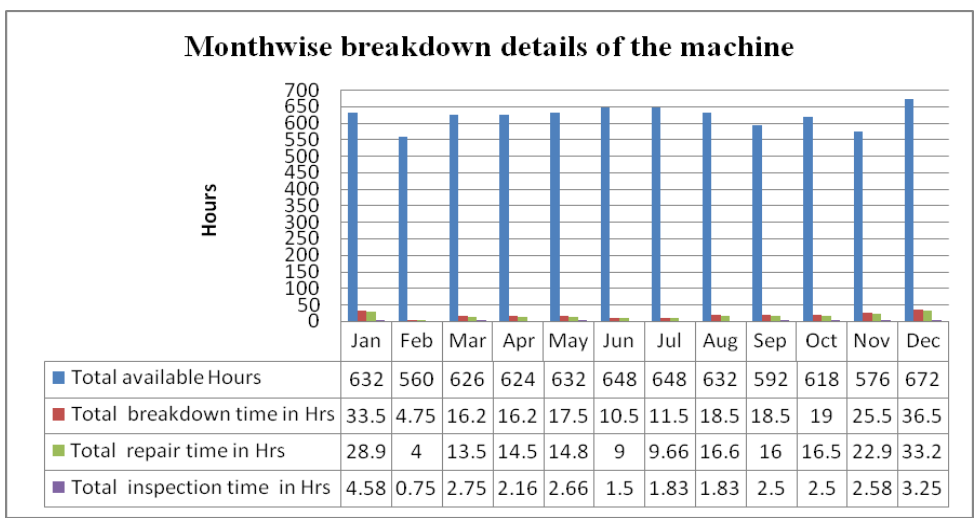

Fig. 2. Bar chart showing monthwise breakdown details for Intermix and Dump mill

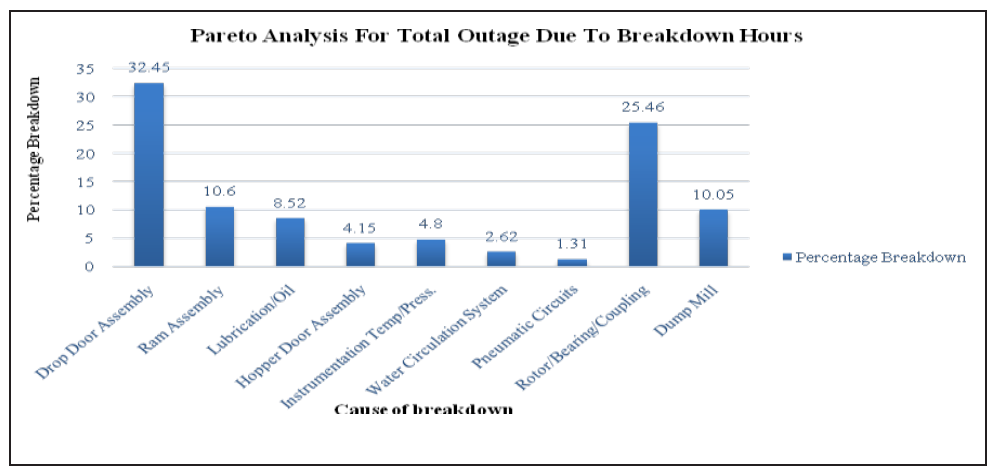

Fig. 3. Pareto chart for Intermix and Dump mill

\subsubsection{Total loss in Rupees due to breakdown of 228.75 hrs}

This will be equal to the product of Breakdown hours, Production loss/hour and Average profit $/ \mathrm{kg}$ of compound $=228.75 \times 1608.6 \times 5=$ Rs. $18,39,836$.

\subsubsection{Total rubber compound lost in the year due to Butyl change **}

This will be equal to the product of time lost in butyl change and production loss/hour = $96.25 \times 1608.6=154.82$ tons.

\subsubsection{Total loss in rupees due to butyl change}

This will be equal to the product of time lost in butyl change, production loss/hour and Average profit $/ \mathrm{kg}$ of compound $=96.25 \times 1608.6 \times 5=$ Rs. 7,74,139. 
** Butyl changeover time is the time taken to clean the intermix so that butyl compound is processed. This is not the machine failure and but is a part of the system.

Similarly production loss due to all nine major repetitive causes of breakdown were found and tabulated (table 3). Details of production loss (in tons) due to spares and inventory cost, man hour losses, utility losses and overhead expenses were not available.

Table 3. Production loss (in tons) for the year for Intermix and Dump mill

\begin{tabular}{|c|l|c|c|c|}
\hline $\begin{array}{c}\text { SI. } \\
\text { No. }\end{array}$ & Cause of breakdown & $\begin{array}{c}\text { Breakdown } \\
\text { in hours }\end{array}$ & $\begin{array}{c}\text { Percentage } \\
\text { breakdown }\end{array}$ & $\begin{array}{c}\text { Compound Lost due } \\
\text { to breakdown in tons }\end{array}$ \\
\hline 1 & Drop Door Assembly & 74.25 & 32.45 & 119 \\
\hline 2 & Ram Assembly & 24.25 & 10.60 & 39 \\
\hline 3 & Lubrication oil flow & 19.5 & 8.52 & 31.36 \\
\hline 4 & Hopper Door & 9.5 & 4.15 & 15.28 \\
\hline 5 & $\begin{array}{l}\text { Instrumentation } \\
\text { Température/Pressure. }\end{array}$ & 11 & 4.86 & 17.69 \\
\hline 6 & Water circulation & 6 & 2.62 & 9.65 \\
\hline 7 & Pneumatic flow & 3 & 1.31 & 4.82 \\
\hline 8 & Rotor/bearing Coupling & 58.25 & 25.5 & 93.7 \\
\hline 9 & Dump Mill & 23 & 10.05 & 37 \\
\hline
\end{tabular}

\subsection{Cause and Effect Diagram or Fish Bone Diagram}

The Pareto analysis and the histograms have identified five subsystems of the intermixer and dump mill as the areas of repetitive failures. They include - Drop door assembly, Ram assembly, Lubrication and process oil circulation, Dump mill and Hopper door. A systematic brainstorming session would yield the different causes of failure and the corrective actions to be taken to eradicate those causes. Brainstorming session for drop door assembly problem resulted in the following causes and corrective actions.

\subsubsection{Causes of Failure and Corrective Actions for Drop Door Assembly problem:}

As the repetitive breakdowns of the drop door assembly are highest, an effective maintenance strategy has to be planned in order to bring down the frequency of failure of this part. The causes for the failure and their corrective actions are as follows:

- Wear and tear, shearing of drop door of latching pins: It is due to vibrations of ram injector and overloading of the intermixer. Hence stop overfeeding and maintain feeding as specified by the manufacturer. When pins are worn out, arc welding is done and finished to size by grinding. Timings of latch operations have to be inspected periodically to avoid pin shearing. Failed pins must be replaced.

- Improper lubrication: It leads to drop door struck. It is due to malfunctioning of hydraulic system, leakage in clamping cylinder and assembly and malfunctioning of thermocouple. Corrective actions include checking oil circulation system and pressure gauges periodically. Check oil level/water level in thermocouple.

- Scorching of the rubber compound: This leads to heavy loss till the defect is solved. Overheating causes scorch. Corrective action include checking cooling water circulation system and rectifying the defect, checking water pump and valves for proper functioning. 
- Hinge block problem: Strucking of hinge blocks during opening or closing of drop door can be corrected by periodically inspecting hydraulic pressure, operating cylinders, pump and motor.

Brainstorming session for the remaining four problems were conducted and resulted causes and corrective actions were identified. A Fishbone Diagram showing five major subsystems and their causes of failure is shown in the figure 4. A troubleshooting chart showing description of the problem and proposed action plan is shown in the table 4 .

The bar charts and histograms show the monthwise available hours and total breakdown time for each month which include all the causes of breakdown. Pareto charts help to identify the contributing or major factors for the failure of the equipment, thus focussing our attention on the elimination of these causes. A detailed brainstorming session on each of these major factors help us to identify all possible causes for the failure of the system. These primary and secondary causes can then be used to draw the fishbone diagram and troubleshooting chart, which help to reduce the breakdowns, thus increasing the productivity of the machine.

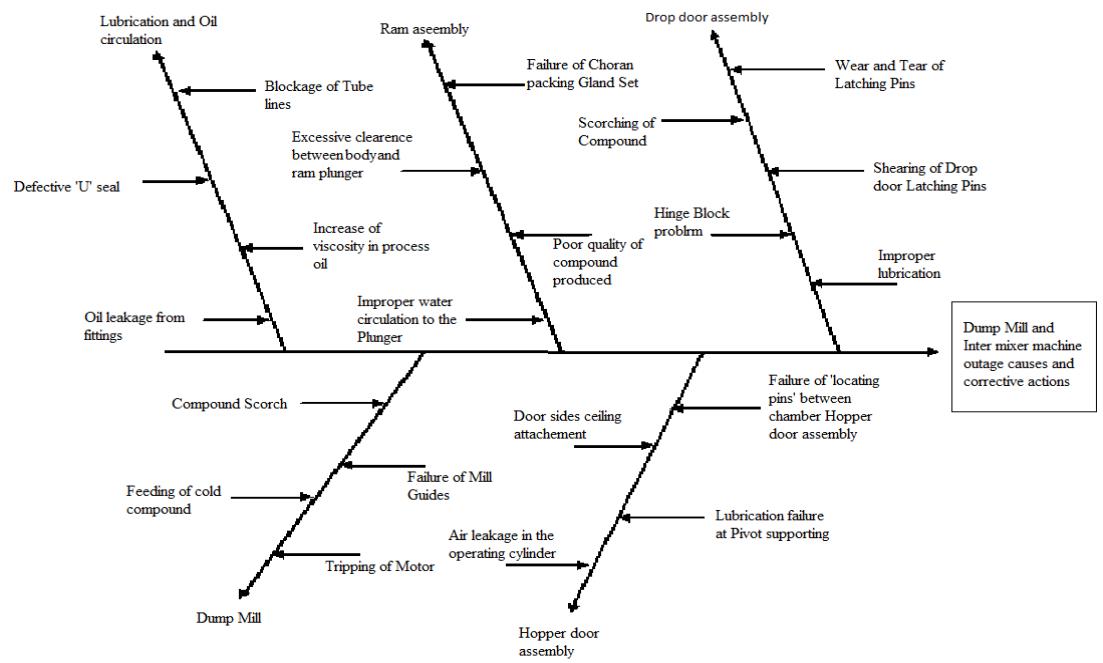

Fig. 4. Cause and Effect diagram or Fishbone diagram for the intermixer and dump mill

\subsection{Reliability assessment of the Intermixer and Dump mill (Theoretical)}

Total number of available hours, repair hours and breakdown hours in the year are found to be $7460,199.8$ and 228.75 respectively. Total number of breakdowns or number of maintenance actions taken in the year equal to 83. Some of the important factors such as failure rate, Mean time between failures (MTBF), Mean time to repair (MTTR), maintenance action rate, maintainability rate and availability are calculated for assessing the reliability theoretically.

\subsubsection{Failure rate}

Failure rate, $\lambda=($ Total No. of failures $) /($ Total available hours $)=0.011$ breakdowns $/$ hour. 


\subsubsection{Mean Time Between Failures (MTBF)}

$\mathrm{MTBF}=($ Total available time $) /($ Number of break downs or failures $)=89.87$ hours.

\subsubsection{Maintenance action rate}

Maintenance action rate, $\mu=($ No. of maintenance action $) /($ Total repair time $)=0.415$ per $\mathrm{hr}$.

\subsubsection{Mean Time To Repair (MTTR)}

MTTR $=($ Total repair hours $) /($ No. of maintenance action taken $)=2.40$ hours per action.

Table 4. Troubleshooting Chart for Intermixer and Dump Mill

\begin{tabular}{|c|c|c|c|}
\hline Sl. No. & Problem & Corrective action proposed & Remarks \\
\hline 1 & Motor does not start/trips & $\begin{array}{l}\text { Check for power, fuse, short } \\
\text { circuit }\end{array}$ & $\begin{array}{l}\text { Refer to electrical } \\
\text { maintenance. }\end{array}$ \\
\hline 2 & Compound scorch & $\begin{array}{l}\text { Uneven water circulation. } \\
\text { Improper circulation of water } \\
\text { in ram. Scale formation inside } \\
\text { the mill roller. }\end{array}$ & $\begin{array}{l}\text { Check water quality if it is a } \\
\text { repetitive problem. Remove } \\
\text { scales. Check water } \\
\text { circulation. }\end{array}$ \\
\hline 3 & $\begin{array}{l}\text { Compound coming out of } \\
\text { the chamber }\end{array}$ & U seal may be defective. & Replace if necessary. \\
\hline 4 & $\begin{array}{l}\text { Compound dust coming out } \\
\text { through hopper door }\end{array}$ & $\begin{array}{l}\text { Door sides scaling attachment } \\
\text { defective. Failure of flat } \\
\text { springs in sealing strips. The } \\
\text { dust bag might be blocked. } \\
\text { Check for correct insertion of } \\
\text { locating pins. }\end{array}$ & $\begin{array}{l}\text { Check and replace if } \\
\text { necessary. } \\
\text { Clean the dust bag or filter } \\
\text { bag. } \\
\text { Locating pins may be } \\
\text { relocated during overhauling }\end{array}$ \\
\hline 5 & $\begin{array}{l}\text { Water leak into the chamber } \\
\text { of internal mixer and dump } \\
\text { mill }\end{array}$ & $\begin{array}{l}\text { Improper water circulation to } \\
\text { the plunger. Check all hoses, } \\
\text { nipples. }\end{array}$ & $\begin{array}{l}\text { Recirculate and check for } \\
\text { water pressure. }\end{array}$ \\
\hline 6 & $\begin{array}{l}\text { Varying oil content in the } \\
\text { compound }\end{array}$ & $\begin{array}{l}\text { Viscosity of the process oil } \\
\text { might be altered. Check the } \\
\text { heating pads. }\end{array}$ & $\begin{array}{l}\text { Make sure that the process } \\
\text { oil is maintained at specified } \\
\text { temperature. }\end{array}$ \\
\hline 7 & Drop door limit switch & $\begin{array}{l}\text { Drop door not operated } \\
\text { properly due to malfunctioning } \\
\text { of limit switches. }\end{array}$ & Replace limit switches. \\
\hline 8 & $\begin{array}{l}\text { Compound smoke coming } \\
\text { from U seals and glands }\end{array}$ & $\begin{array}{l}\text { Lubrication failure. } \\
\text { Lubrication lines blocked. } \\
\text { Wrong selection of lubrication } \\
\text { oil. }\end{array}$ & $\begin{array}{l}\text { Check for leaks and select } \\
\text { right lubricant. Replace U } \\
\text { seals and glands if necessary. }\end{array}$ \\
\hline 9 & $\begin{array}{l}\text { Compound lump being } \\
\text { thrown out from the mill }\end{array}$ & $\begin{array}{l}\text { Wrong direction of rotation of } \\
\text { mill rollers. }\end{array}$ & $\begin{array}{l}\text { Counsel or train the } \\
\text { employees properly. }\end{array}$ \\
\hline 10 & Slow Ram movement & $\begin{array}{l}\text { Check air pressure and the } \\
\text { valves. }\end{array}$ & Inspect respectively. \\
\hline 11 & $\begin{array}{l}\text { Excessive vibration of the } \\
\text { machine }\end{array}$ & $\begin{array}{l}\text { Check for bearing bushes, ram } \\
\text { clearance and rotor pinions. }\end{array}$ & $\begin{array}{l}\text { Apply proper lubricant. Stop } \\
\text { the machine to find out the } \\
\text { cause. }\end{array}$ \\
\hline
\end{tabular}




\subsubsection{Maintainability Rate}

$$
\text { Maintainability Rate, } M=\left[1-\mathrm{e}^{-\mu t}\right]
$$

where ' $t$ ' is time (hours) and ' $\mu$ '= Maintenance action rate. Maintainability Rate for $1,2,3$, $5,10,20$ and 25 hours are found and plotted as shown in maintainability curve (figure 5).

\subsubsection{Availability}

$$
\text { Availability, } A_{e}=\left\{1-\left[\mathrm{e}^{-(\mu / \mathrm{MTTR})}\right]\left[1-\mathrm{e}^{-(t / \mathrm{MTBF})}\right]\right\}
$$

where $\mu=0.415$ repairs/hour, MTTR $=2.40$ hours/maintenance action, MTBF $=89.87$ hours and $t$ in Hours. Availability for 1, 5, 10, 25, 50, 100 and 200 hours are found and plotted as shown in the availability curve (figure 6).

\subsubsection{Reliability}

$$
\text { Reliability, } R=\mathrm{e}^{-(\lambda t)}
$$

where failure rate, $\lambda=0.011$ breakdowns/hour and ' $t$ ' time in hours. Reliability for $1,5,10$, $25,50,100$ and 200 hours are found and plotted as shown in the reliability curve (figure 7).

From the curves shown in figures 6 and 7, it can be concluded that availability and reliability of the machine decreases with the passage of time, as the machine parts are subjected to wear and tear and deterioration. Availability and reliability may be brought back to the initial level by conducting maintenance activities. From the figure 5 it can be concluded that the maintainability of the machine increases with the passage of time, which in turn increases availability and reliability. Further, it can be seen that reliability and maintainability are the two factors which influence the availability of the plant.

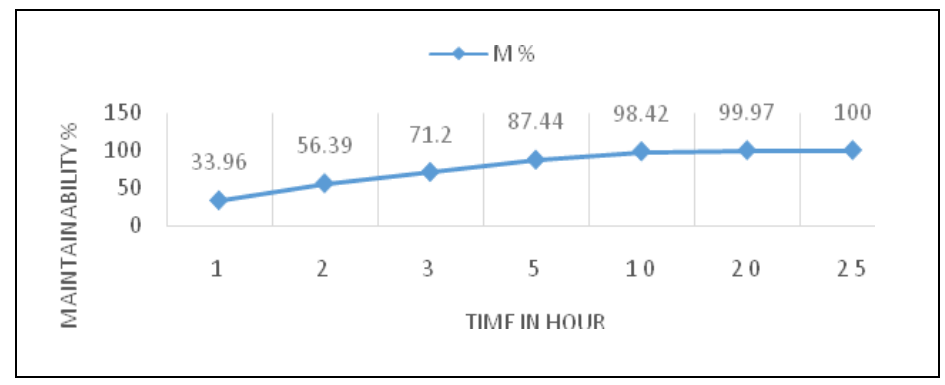

Fig. 5. Maintainability curve for intermixer and dump mill 


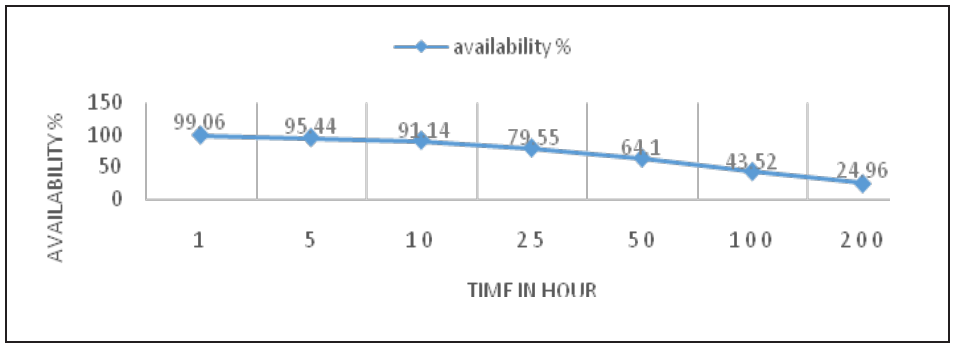

Fig. 6. Availability curve for intermixer and dump mill

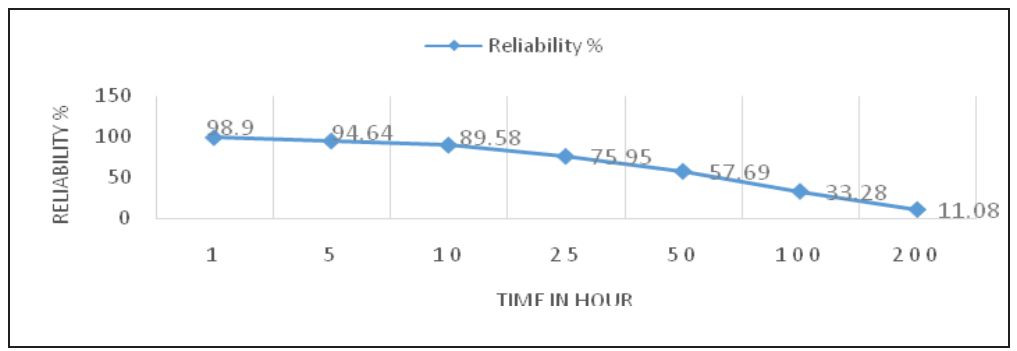

Fig. 7. Reliability curve for intermixer and dump mill

\section{Conclusions}

This work has been carried out on intermixer and dump mill based on the failure data collected for one year. The major causes for failures have been analyzed with the help of quality control tools such Pareto chart and Fishbone diagram. A bar chart and histogram helps to find out all possible machine breakdown hours for the selected period. A Pareto analysis breaks a big problem down into smaller pieces and identifies the most significant factors. Fishbone diagram helps to identify primary and secondary causes for the failures. Actions plans for the root causes of the problems were suggested and a troubleshooting chart was prepared. Thus, bar chart and histograms, Pareto chart and fish bone diagrams help us in the identification of possible causes of breakdown and to eliminate these causes so that machine availability and productivity can be enhanced. Analysis of the failure data could be further used in preparing the new preventive maintenance inspection schedule for the critical parts of the machine. Existing schedule can be modified based on the failure data analysis.

Reliability and maintainability are the two factors which influence the availability of the plant. Maintainability curves will speak about the present state of working of maintenance department in regard to addressing of breakdown problems. The curves of reliability and availability of the intermixer and the dump mill for the year can be compared to the already set performance standards of the machine in future years. It will be useful to carry out this kind of work on each and every machine in the plant so that any deviation from the set performance standards could be identified and resolved to improve the productivity of the machines. 


\section{References}

1. L. R. Higgins, Maint. Engg. Handbook, 5 Ed, (1995)

2. A. Kelly, M.J. Harris, Mgmt. of Ind. Maint, (1978)

3. L.S. Srinath, Reliability Engg, 3 Ed, (1991)

4. T. Nath, D. Deka, Int. J.of Engg. Trends Tech, 28, 7 (2015).

5. M. Prashanth Pai, M. S. Prabhuswamy, C. V. Pujar, K. S. Shankar, ICETE-11, 5 (2011)

6. Praveen Kumar, R. Rudramurthy, Int. J. of Em. Tech. Adv. Engg, 3, 10 (2013).

7. Deepak, D. Dhingra, Int. J. of Res. in Engg. Tech, 5, 9 (2016)

8. J. Chandrakar, Rajesh Kumar, Int. J. of Adv. Engg. Res. Studies,4, 3 (2015) 